\title{
Experimental Studies on Fibre Integrated Lightweight Concrete Frames Under Lateral Forces: A Review
}

\author{
M. Muthulakshmi ${ }^{1}$ and M. Vinod Kumar ${ }^{2}$ \\ ${ }^{1}$ Post graduate student, ${ }^{2}$ Assistant Professor, \\ PSNA College of Engineering and Technology, Dindigul, Tamil Nadu, India \\ E-Mail: muthulakshmimaruthanayagam@gmail.com, m.vinodkumar.civil@gmail.com
}

\begin{abstract}
Reinforced Concrete (RC) framed structure with masonry infill is the most common type of building in which, RC frames participate in resisting lateral forces. The poor performance of $\mathrm{RC}$ frame buildings under lateral forces is due to its heavy mass and rigid construction. Use of Lightweight concrete (LWC) is preferred since the dead load of concrete is enormous. A low density of the LWC, decreases the weight of the building thus reducing the effect of lateral forces. However, LWC having a lower modulus of elasticity, has a faster rate of crack development in RC members. So, fibres are employed as an additive to increase the energy absorption capacity and to control the crack development. Pumice is a natural material of volcanic origin, has low density, which makes it ideal for production of LWC. Based on these ideas, Pumice aggregate is used as a partial replacement of coarse aggregate to its volume with addition of steel fibres to the volume of concrete. This paper summarizes the collected literatures related to RC frames, LWC, Fibre Reinforced Concrete (FRC) and thereby attempts to predict the lateral load response of RC portal frame with the use of LWC and Steel fibres.

Keywords: Lateral force, Pumice aggregate, RC portal frame, Steel fibre
\end{abstract}

\section{INTRODUCTION}

A typical Reinforced Concrete (RC) building is made of horizontal members (beams and slabs) and vertical members (columns and walls) supported by foundations that rest on ground, the system comprising of RC frame. The RC frame participates in resisting the lateral forces. High density of the concrete increases the dead loads of the buildings. Therefore, the earthquake and foundational loads increase. In order to eliminate this drawback of the concrete, the density needs to be decreased. One of the concrete types produced for this aim is the lightweight concretes.

Lightweight concrete (LWC), having a lower density when used in a building, dead load and earthquake forces decrease. This minimizes the sections of the building members, makes the foundational problems more economical and decreases the cost of the building. A lower elasticity module in the lightweight concrete accelerates the development of cracks. Therefore, using lightweight concrete in the reinforced concrete may have an adverse effect. However, for the improvement of the concrete characteristics, fibres are used. The significant role of fibres is resisting the formation and growth of cracks. In addition it enhances flexural strength and fatigue strength of reinforced concrete. The concrete with steel fibre as additive are used in reinforced concrete frames, reinforced concrete beam members, highways, tunnel linings, concrete pipes, shell roof systems, light shell constructions, skyscrapers and domes in recent years. With steel fibres as additive to the lightweight concretes, its loading capacity is increased, the cracks are controlled and it shows a great resistance to dynamic and sudden loadings while decreasing the crack width. Furthermore, it also increases the resistance of the concrete against deformation and increases the tensile strength. By adding steel fibres into lightweight concrete, it is stated that the strength of ordinary concrete is neared, it increases the concrete's tensile strength, toughness, flexural strength, resistance to disintegration and breaks, strength against blast effects and ability to deform and economical solutions are reached by decreasing the weight of the building.

\section{PRIOR STUDY ON RC FRAMES}

Sidi Shan et al., (2016) conducted an experimental study on the progressive collapse of frames with and without infill walls and the failure mechanism of two frames were proposed. The frame specimens were quasi-statically pushed to investigate the progressive collapse mechanism of the RC frames. The test results showed that the infill walls can provide alternative load paths for transferring the loads and thus, improve the collapse resistance capacity of the RC frame. The infill walls, however, reduce the ductility of the $\mathrm{RC}$ frame and may change the failure mode of the frame. It was concluded that the infill walls impair the performance of RC frames against progressive collapse.

Abdel-Hafez et al., (2015) conducted an experimental study on the behaviour of different single storey frames under the in-plane lateral load influence. Three phases of frames were tested. The first phase was conducted on individual reinforced concrete bare frame used as control frame. The second phase was conducted on frame infilled with masonry. The third phase was strengthened with Glass fibre reinforced polymer sheets and ferrocement meshes were also used to improve the behaviour. The frame specimens were tested under slow-cyclic displacement loading applied at the slab level using servo-controlled hydraulic actuator of $250 \mathrm{kN}$ load capacity and a stroke length of ${ }^{+} 125 \mathrm{~mm}$. Three cycles of each displacement level were applied and 
the response was recorded using a data acquisition system. LVDTs were used at different locations on the columns and base beam to record the lateral displacements. Base beam was restricted from sliding by bolting it to a strong floor. Maximum lateral load resistance of the specimens was reported in both push (-) and pull (+) directions. It is concluded that the non-ductile bare frame exhibited higher amount of pinching when compared to the ductile frame, and therefore dissipated lesser amount of energy and the dropdown in load carrying capacity was gradual in case of ductile frames when compared to corresponding non-ductile frames. The crack pattern observed in both ductile and nonductile bare frames were similar, but in non-ductile frames, the cracks were initiated earlier and the amount of cracks developed was higher than the ductile frames.

\section{PRIOR STUDY ON LIGHTWEIGHT CONCRETE}

Hasan Oktay et al., (2015) did an experimental investigation for producing relatively high strength and low density concrete. Different types of lightweight aggregates were used including Pumice Aggregates (PA), Expanded Perlite (EPA) and Rubber Aggregates (RA) at different volume fractions of $10 \%, 20 \%, 30 \%, 40 \%$ and $50 \%$. The investigation revealed that the addition of PA, EPA and RA reduced the material bulk density and compressive strength. It was found that the concrete made with $20 \%$ of pumice aggregates had better mechanical properties.

Kashyap et al., (2006) did an experimental investigation on compressive strength of steel fibre reinforced light weight aggregate concrete. Investigation was carried out with $10 \%$, $20 \%$ and $30 \%$ replacement of natural coarse aggregate by pumice aggregate and with $1 \%$ and $1.5 \%$ volume fractions of fibre. Hooked end steel fibres were used. From the experimental results, it is concluded that the density of concrete was found to decrease with increase in percentage replacement of natural aggregate by pumice aggregate and the compressive strength of concrete was found to decrease with increase in pumice content. But, with the addition of steel fibre, the compressive strength of the mixes had proved effectively while comparing with the other mixes.

Desai et al., (2013) have studied on fibre reinforced light weight aggregate (Pumice stone) concrete. In this study, the mix design was M20 and test results are as follow. The target mean strength was achieved with $20 \%$ replacement of natural coarse aggregate by pumice aggregate and with $1.5 \%$ of fibre. Also with $40 \%$ pumice and with $0.5 \%$ of fibres average target mean strength of M20 concrete was achieved.

Minapu et al., (2014) carried out an experimental study on the mechanical properties of a structural light weight concrete using the light weight aggregate pumice stone as a partial replacement of coarse aggregate and mineral admixture like Silica Fume and Fly Ash. It was concluded that, by using $20 \%$ of light weight aggregate as a partial replacement to natural coarse aggregate, the compressive strength was promising.

\section{PRIOR STUDY ON STEEL FIBRES}

An experimental study was conducted by Danah Saraireh et al., (2016) on the behaviour of the normal concrete and the concrete with different types of fibre (steel, macropolypropylene and micro-polypropylene fibres). In this study, the compressive strength, split tensile strength, density and workability of concrete were determined for varied fibre content ranging from $1 \%$ to $4 \%$ volume fraction. Based on the experimental results, it is concluded that the addition of steel fibres increased the tensile strength twice than that of the tensile strength of normal concrete. The test results also show that the use of steel, macropolypropylene and micro-polypropylene fibres changes the failure types to ductile failures, thus overcoming the brittleness problem of the concrete and improves the split tensile strength.

A case study was done by Volkan Tabak et al., (2007) on the effects of aspect ratio (l/d) and volume fraction $\left(V_{f}\right)$ of steel fibre on the compressive strength, split tensile strength, flexural strength and ultrasonic pulse velocity of steel fibre reinforced concrete. Hooked-end steel fibres with three different $1 / d$ ratios of 45,65 and 80 were used. Three different fibre volumes were added to concrete mixes at $0.5 \%, 1.0 \%$ and $1.5 \%$ by volume of concrete. From the experimental results it was found that, inclusion of steel fibres significantly affect the split tensile and flexural strength of concrete accordance with $\mathrm{l} / \mathrm{d}$ ratio and $\mathrm{V}_{\mathrm{f}}$. The increase in flexural strength of SFRCs was significantly improved with increasing $\mathrm{l} / \mathrm{d}$ ratio and $\mathrm{V}_{\mathrm{f}}$. SFRCs with aspect ratio of 80 had highest compressive strength at $1 \%$.

Sofiane Amziane et al., (2016) conducted an experimental study on flexural behaviour of fibre reinforced concrete under cyclic loading. Prismatic concrete specimens having the dimensions of $150 \times 150 \times 700 \mathrm{~mm}$ were fabricated and reinforced with hooked end steel fibres of aspect ratios of 65 and 80 at contents of 0.5 and 1\%. A four point bending test with notched specimens was conducted using Digital Image Correlation technique. The orientation of the fibres, failure modes, flexural strength, cumulative energy and ductility of FRC beams were presented and analyzed. The experimental results shown that the cyclic flexural behaviour of FRC, flexural strength and ductility of fibrereinforced concrete are significantly improved by the fibre content, aspect ratio, the fibres orientation and the concrete strength. The workability of concrete plays an important role in the orientation and distribution of fibres in the matrix. The test results showed that all FRC structural beams under cyclic loading were able to show ample ductility before failure. The post-peak behaviour is considerably improved, exhibiting a marked softening of the material, preventing the energy from being liberated instantaneously in case of failure, but rather gradually in a soft manner. 
Simoes et al., (2017) did an experimental analysis on the mechanical behaviour of fibre reinforced concrete matrixes (FRCM) with three types of fibres to reinforce it (polypropylene, glass and steel fibres). Within each type of reinforcement, four volumetric proportions were adopted, ranging from $0.5 \%$ to $2 \%$ in $0.5 \%$ increments. The influence of each type of fibre and dosage on the properties of the FCRM, including the compressive strength, bending behaviour, cracking and maximum loads and ductility was analysed. From the experimental results it is concluded that, the steel fibres provided the composite material a better capacity to withstand high deformations. Results also show that the compressive strength grows according to the tensile strength and stiffness of the fibre, being lower for polypropylene and larger for steel fibres. Regarding the flexural behaviour, a ductile behaviour is observed if fibres also exhibit a ductile behaviour, as in case of steel fibres and a fragile behaviour, as in the case of glass fibres. With the increase in the fibre tensile strength, the maximum load also increases. For steel fibres, the increase in fibre content leads to increase of both toughness index and energy absorption capacity.

\section{SALIENT POINTS FROM FORMER WORKS}

The dropdown in load carrying capacity of RC frame under lateral forces can be made gradual by improving its ductility.

1. The addition of steel fibres to concrete, change the failure types to ductile failure, thus overcoming the brittleness problem of concrete.

2. The ductility is improved with increasing aspect (l/d) ratio and Volume fraction $\left(\mathrm{V}_{\mathrm{f}}\right)$ of steel fibres.

3. Upto $1 \% \mathrm{~V}_{\mathrm{f}}$ of steel fibres, the strength of fibrereinforced concrete (FRC) is promising.

4. Density of concrete decreased with increase in percentage replacement of coarse aggregate by pumice aggregate.

5. Upto $20 \%$ replacement of pumice aggregate as a partial replacement of coarse aggregate, better strength is achieved.

\section{RESEARCH GAP}

A comprehensive study was undergone by gathering a broad range of research articles. By conducting a detailed literature review, it was found that enormous experimentation has been done on RC frames with and without infill under lateral forces. Although there has been extensive work done on the mechanical properties of LWC and FRC, there was no relevant research regarding the inelastic behaviour of those under lateral load conditions. To use LWC, designed for inelastic flexural deformation, it is necessary to assess the behavior of the material in terms of stiffness, displacement capacity and energy absorption characteristics. This area has not yet been explored.

\section{SCOPE FOR FUTURE RESEARCH}

Despite an extensive examination has been done in the field of RC frames under lateral forces. Future research is necessary to understand the displacement capacity, energy absorption and inelastic behaviour of Fibre Reinforced Lightweight Concrete frames under seismic loads.

\section{CONCLUSION}

1. Structural seismic responses are based on mass of the structure or dead weight of the structure, thus the selection of materials to maintain the dead weight low should be adopted. Thus, LWC can be employed to undergo large inelastic deformation during extreme earthquakes.

2. But, the performance of LWC buildings is questionable because of its brittle nature. In order to use LWC for flexural deformation, fibres can be used as they delay the formation of macro-cracks as well as resists the propagation of micro-cracks. The effect of slowing down of the crack propagation leads to an enhanced ductility thereby facilitating increased deflection without causing complete collapse.

3. A ductile behaviour is observed if fibres also exhibit a ductile behaviour, as in case of Steel fibres. With the increase in the fibre tensile strength, the maximum load also increases. For steel fibres, the increase in fibre content leads to increase of both toughness index and energy absorption capacity.

4. On the whole, LWC reduces the seismic mass, consequently the earthquake response can be diminished. On incorporating Steel fibres, enhances the ductility by arresting cracks therby facilitating increased defection. Thus, LWC RC frames when reinforced with Steel fibres are expected to show better performance under lateral forces.

\section{REFERENCES}

[1] Bensaid Boulekbache, Mostafe Hamrat, Mohamed Chemrouk and Sofiane Amziane, "Flexural behaviour of steel fibre reinforced concrete under cyclic loading”, Construction and Building Materials, Vol. 126, pp. 253-262, 2016.

[2] Hasan Oktay, Recep Yumrutas and Abdullah Akpolat, "Mechanical and thermophysical properties of lightweight aggregate concretes”, Construction and Building Materials, Vol. 96, pp. 217-225, 2015.

[3] Kashyap and Sasikala, "An experimental study on Compressive Strength of steel fibre reinforced lightweight aggregate concrete", Vol. 9, pp. 21-25, 2014.

[4] Lakshmi kumar Minapu and Ratnam, "Experimental study on LWAC with Pumice stone as a partial replacement of coarse aggregate”, Vol. 3, pp. 43-45, 2014.

[5] Lila Abdel-Hafez, Abouelezz and Faseal Elzefeary, "Behaviour of masonry strengthened infilled reinforced concrete frames under inplane load”, Housing and Building National Reasearch Journal, Vol. 11, pp. 213-223, 2015.

[6] Messaound Saidani, Danah Saraieh and Michael Gerges, "Behaviour of different types of fibre reinforced concrete without admixture”, Engineering Structures, Vol. 113, pp. 328-334, 2016.

[7] Semsi Yazici, Gozde Inan and Volkan Tabak, "Effect of aspect ratio and volume fraction of steel fibre on the mechanical properties of SFRC”, Construction and Building Materials, Vol. 21, pp. 12501253, 2007. 
Experimental Studies on Fibre Integrated Lightweight Concrete Frames Under Lateral Forces: A Review

[8] Sidi Shan, Shauang Li, Shiyu Xu and Lili Xie, "Experimental study on the progressive collapse performance of RC frames with infill walls”, Engineering Structures, Vol. 111, pp. 80-92, 2016.

[9] Simoes, Costa and Julio, "Influence of fibres on the mechanical behaviour of fibre reinforced concrete matrixes", Construction and Building Materials, Vol.137, pp. 548-556, 2017.
[10] Sivalinga Rao and Bhaskar Desai, "Fibre reinforced lightweight aggregate concrete”, Vol. 3, pp 27-34, 2013. 